\title{
Longitudinal Reciprocal Relationships Between Subjective Social Status and Short Sleep Duration in a German Population-Based Sample
}

\author{
Frank Euteneuer ${ }^{1,2}$ \\ Philipp Süssenbach ${ }^{3}$ \\ 'Department of Psychology, Clinical \\ Psychology and Psychotherapy, Medical \\ School Berlin, Berlin, Germany; ${ }^{2}$ Division \\ of Clinical Psychology and Psychotherapy, \\ Philipps University of Marburg, Marburg, \\ Germany; ${ }^{3}$ Fachhochschule des \\ Mittelstands (FHM) Bielefeld-University \\ of Applied Sciences, Bielefeld, Germany
}

Correspondence: Frank Euteneuer Department of Psychology, Clinical Psychology and Psychotherapy, Medical School, Berlin, Rüdesheimer Str. 50, Berlin, 14197, Germany

Tel +49307668375820

Email frank.euteneuer@medicalschoolberlin.de
Objective: Low socioeconomic status is associated with short sleep duration. Most studies in this area have used measures of objective socioeconomic status (OSS) such as income, education, or occupation. Subjective social status (SSS) refers to one's perceived standing in the social hierarchy. Cross-sectional findings suggest that lower SSS is associated with short sleep duration beyond the effect of OSS. This work examines longitudinal associations between SSS, OSS, and short sleep duration.

Methods: Reciprocal associations of national SSS (ie, comparison with people in one's country), local SSS (ie, comparison with people in one's social environment), and OSS (ie, income and education) with sleep duration were examined across two data waves with a two-year time lag using cross-lagged panel modeling. Participants of this secondary analysis were 2156 individuals who participated in a representative German panel.

Results: Lower national SSS (but not local SSS) and lower income at baseline predicted short sleep duration at follow-up. When considering indicators of SSS and OSS simultaneously, only national SSS remained a significant predictor of short sleep duration. A halflongitudinal mediation analysis indicated that national SSS mediates associations between lower OSS and short sleep duration.

Conclusion: One's perceived socioeconomic position in the country is a relevant predictor of short sleep duration and could be a psychological link between OSS and short sleep duration as mediation analyses suggest. Future studies on socioeconomic status and sleep should thus take into account subjective measures of socioeconomic status to gain a clearer picture of the social determinants of sleep.

Keywords: socioeconomic status, subjective social status, short sleep duration, cross-lagged panel

\section{Introduction}

A recent meta-analysis indicated that short sleep - defined as a sleep duration of less than six hours per day- is associated with a significant increase in mortality, diabetes, cardiovascular disease, coronary heart disease, and obesity. ${ }^{1}$ Individuals with lower socioeconomic status are more likely to be short sleepers. ${ }^{2-9}$ The well-documented adverse health impact of a low socioeconomic position ${ }^{10}$ may thus be partly mediated by a reduction in sleep duration. ${ }^{11,12}$ Explanations which have been discussed for the link between low socioeconomic status and short sleep include adverse environmental conditions, occupational circumstances, and the need to maximize available time for work. ${ }^{11}$ With respect to psychological mechanisms, the perception of a low social 
position may be accompanied by greater worry and rumination due to employment concerns and financial insecurity, a need to be more vigilant, as well as the experience of negative emotions and stress-related psychobiological alteration - all these factors may influence the ability to maintain an adequate amount of sleep. ${ }^{3,11-13}$

Most studies examining the relation between social status and short sleep relied on objective measures of socioeconomic status (OSS) such as income, education, or occupation. ${ }^{2,4-9}$ In the last two decades, a growing number of studies found that subjective social status (SSS) relates to multiple health outcomes over and above OSS. ${ }^{14,15}$ SSS refers to an individual's perceived position in the social hierarchy. It has been suggested that SSS captures the averaging of OSS markers and may thus mediate, in part, associations between OSS and health. ${ }^{16-18}$ From the perspective that one's relative rather than one's absolute social position is of relevance for health and wellbeing in richer societies, it has also been argued that SSS, in contrast to OSS, captures a psychological facet of social inequality which has unique stress-related psychobiological effects on health. ${ }^{19,20}$ Turning to sleep, low SSS has been found to be associated with reduced sleep duration beyond the effect of OSS in cross-sectional analyses. ${ }^{3,21}$ Although these findings suggest a link between low SSS and short sleep, little is known about reciprocal longitudinal associations between SSS and short sleep.

The present work examined bidirectional longitudinal associations of SSS with short sleep in a representative German population sample using cross-lagged panel modeling with a two-year time lag. We thus aimed to extend previous cross-sectional findings ${ }^{3,21}$ by studying the direction of the relationship between SSS and short sleep. With respect to SSS, we were further interested in potentially diverging effects depending on the reference group that is used for assessing one's social status. Therefore, two indicators of SSS were included to measure individuals' perceived social position relative to people in one's country (ie, national SSS) and to people in one's social environment (ie, local SSS). Unlike national SSS, local SSS captures a broader range of statusrelated aspects beyond socioeconomic factors (eg, perceived respect and social rewards from others, social standing within meaningful social groups). ${ }^{15,22}$ Finally, we examined whether SSS partially mediates associations of OSS (ie, income and education) with short sleep duration. Given the lack of longitudinal research on the relationship between SSS and sleep, the present research should be considered exploratory.

\section{Method}

\section{Data Source}

Data were obtained from the 2016 (i.e, baseline) and 2018 (ie, follow-up) wave of an Innovation Sample of the Socio-Economic Panel (SOEP-IS), a panel study representative for the German population. The annual assessment runs from September to December. The SOEP-IS recruitment based on randomly selected households. The study design and sampling procedures are described elsewhere. ${ }^{23,24}$ The Institutional Review Board of the German Institute of Economic Research (DIW) approved the SOEP. Data are freely available for researchers who work at a scientific research institution after application. Researchers can apply for SOEP data use and receive data on request after completion of a data distribution contract with the DIW. Findings on the longitudinal associations between SSS and health-related quality of life using this sample have been published previously. ${ }^{25}$

\section{Subjective Social Status}

SSS was assessed with the German version ${ }^{26}$ of the MacArthur Scales of Subjective Social Status. ${ }^{27-29}$ These scales are valid measures to assess individuals' subjective social standing. ${ }^{26,30}$ Participants rated their place on two visual 10-rung "social ladders" in relation to those who have the highest and lowest standing in their local social environment (ie, local SSS scale) and to those who are the best and worst off with respect to money, education, and job reputation in Germany (ie, national SSS scale). Lower scores represent lower SSS (range 1-10). While the national SSS scale refers to traditional indicators of socioeconomic status and people in one's country, the local SSS scale gives no criteria for the nature of "social environment" or the dimensions of status to be used. This allows individuals to choose the most meaningful local reference groups for social comparison and to consider a broader range of status-related aspects beyond socioeconomic factors (eg, perceived respect and social rewards from others, social standing within meaningful social groups). ${ }^{15,22}$ The English version of the local SSS scale differs from the German version in the way that it asks individuals about their standing in relation to people in their community when assessing local SSS. Because the word "community" has no semantic equivalent in German, it was replaced by the term "social environment". 26 


\section{Objective Socioeconomic Status}

OSS was assessed by education and household net income $(€ /$ month, free-response question). To equivalize household net income, it was divided by the square root of the household size. ${ }^{31}$ Educational degrees were quantified using the SOEP version of the International Standard Classification of Education (ISCED-1997). ${ }^{32}$ This classification captures the highest degree/diploma attained, considering degrees and diplomas attained in both general schooling and in vocational and university education. The SOEP version of the ISCED differs from the ISCED levels as defined by the Organization for Economic Cooperation and Development (OECD), since all tertiary degrees are included in the highest category. Higher scores indicate higher education (range 0-6).

\section{Sleep Duration}

Participants were asked about sleep duration for weeknights (How many hours do you sleep at night on average on a normal weekday?) and weekends (How many hours at night on a normal weekend day?). For wave 2016 and 2018, average sleep duration was calculated using the following equation ((minutes slept during the week $\times 5)+($ minutes slept during weekends $\times 2)) / 7$. Based on previous metaanalyses, ${ }^{1,33}$ sleep duration was dummy coded as short sleep ( $<6$ hours) and long sleep ( $>8$ hours). Therefore, a sleep duration of 6 to 8 hours represented the reference category.

\section{Statistical Analysis}

To test cross-lagged relations, we specified a set of sex- and age-adjusted two-wave cross-lagged panel models (CLPM) with status-related continuous variables and two dummy variables for short sleep duration and long sleep duration. In a first step, separate CLPMs were run for local SSS (Model A1), national SSS (Model A2), income (Model A3), as well as education (Model A4) to test associations of each measure of SSS and OSS, respectively, with short sleep duration. Thereafter, we examined whether local SSS, national SSS, income, and education have unique longitudinal associations with sleep when considering all measures of social status simultaneously. Figure 1 illustrates the structure for the full model (model B), which was also used to examine half-longitudinal mediations. For this purpose, the product of the estimates for (a) the path from the independent variable at 2016 to the mediator at 2018 (while controlling for the mediator at 2016), and (b) the path from the mediator at 2016 to the outcome at 2018 (while controlling for the outcome at 2016) was used as an estimate of the mediation effect. ${ }^{34}$ All analyses were carried out with Mplus7 (Muthén \& Muthén, 1998-2012) using Bayesian analyses with full-information estimation and included all available data from all participants $(n=2156)$. For the present subsample, a detailed nonresponse analysis was not available. All analyses were conducted under the assumption that data were missing at random (MAR). Although MAR could not be fully verified, it represents the most used assumption about nonresponse in panel data and is a useful approximation even if it is believed to be false. ${ }^{35,36}$

\section{Results}

Table 1 displays descriptive statistics for baseline (2016) and two-year follow-up (2018). A total of 2156 individuals participated in 2016, the baseline wave. Data for this wave were

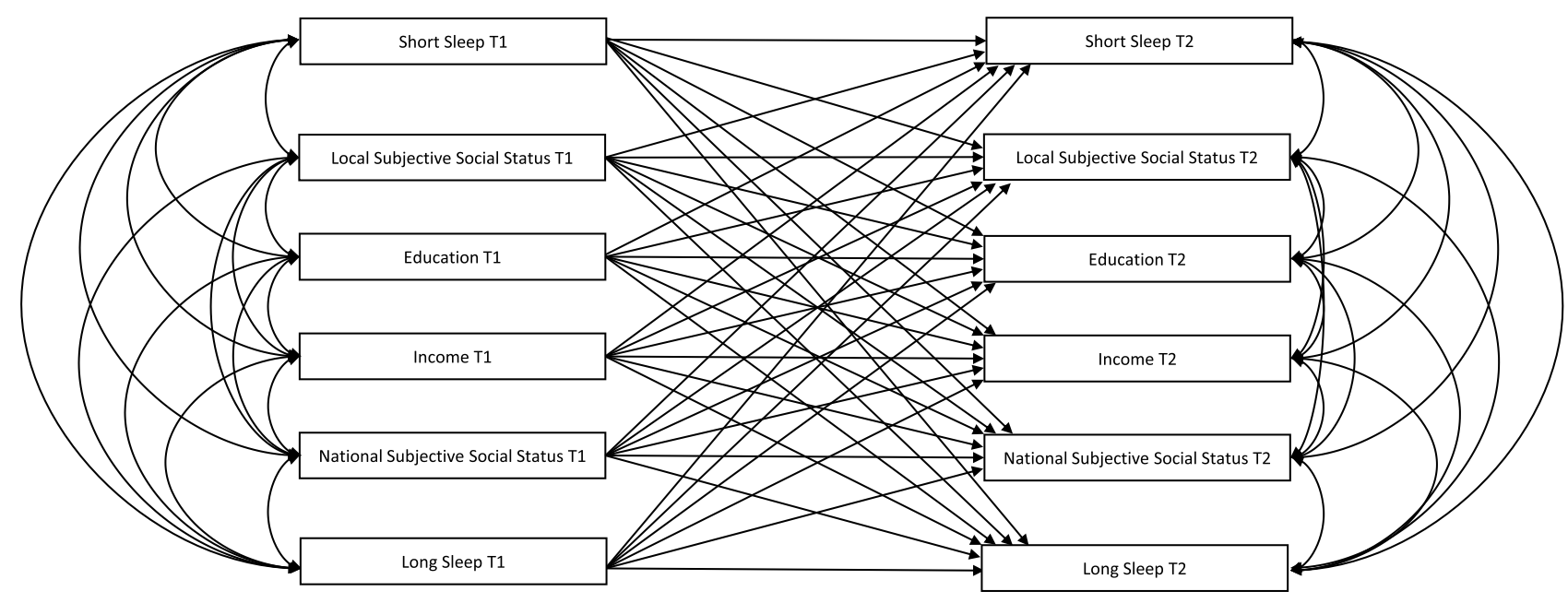

Figure I Specification of the cross-lagged panel model with all study variables (ie, model B; see methods sections for details). For ease of presentation, arrows for covariates (sex and age) are omitted. 
Table I Sample Characteristics at Baseline $(n=2156)$ and Follow- Up $(n=1632)$

\begin{tabular}{|c|c|c|}
\hline Variables & Baseline (2016) & Follow-Up (2018) \\
\hline Age, years & $52.65(18.62)$ & $56.05(17.94)$ \\
\hline Females, $n(\%)$ & $1126(52.2)$ & $857(52.5)$ \\
\hline Education, ISCED-1997 & $3.59(\mathrm{I} .4 \mathrm{I})$ & $3.7 \mathrm{I}(\mathrm{I} .42)$ \\
\hline Household net income $(€)^{\prime}$ & $1946(1021)$ & $2125(1179)$ \\
\hline National subjective social status & $5.80(1.66)$ & $5.66(1.60)$ \\
\hline Local subjective social status & $6.35(1.64)$ & $6.21(1.64)$ \\
\hline \multicolumn{3}{|l|}{ Sleep duration categories } \\
\hline Short $<6$ hours/day, $n(\%)$ & $290(13.5)$ & $214(13.1)$ \\
\hline Reference 6-8 hours/day, $n$ (\%) & I59| (73.9) & $1228(75.4)$ \\
\hline Long >8 hours/day, $n(\%)$ & $27 I(12.6)$ & 187 (I I.5) \\
\hline
\end{tabular}

Notes: Values shown as mean (SD) unless otherwise noted. 'Household net income divided by the square root of the household size.

available as follows: age and sex $(n=2156 ; 100 \%)$, education ( $n=2137 ; 99.12 \%)$, income ( $n=2041 ; 94.67 \%)$, local SSS ( $n=2125 ; 98.56 \%)$, national SSS ( $n=2121 ; 98.38 \%)$ and sleep duration $(n=2152 ; 99.81 \%)$. In 2018, the followup wave, a total of 1632 of the initially 2156 individuals participated. Data for this wave were available as follows: education ( $n=1626 ; 99.63 \%)$, income $(n=1530 ; 93.75 \%)$, local SSS $(n=1616$; 99.02\%), national SSS $(n=1616$; $99.02 \%)$, and sleep duration ( $n=1629 ; 99.82 \%)$.

Table 2 shows estimates for models A1-A4, which separately examined associations of subjective and objective measures of social status with sleep duration. Table 3 summarizes results for model $\mathrm{B}$, which simultaneously examined associations of subjective and objective measures of social status with sleep duration. Results indicated that lower national SSS at baseline, but not local SSS, predicted short sleep duration in model A2 ( $B=-0.07, \beta=-0.09, p=0.020)$ and in model $\mathrm{B}(B=-0.07, \beta=-0.10, p=0.014)$ which included all status indicators simultaneously. In addition, lower income at baseline predicted short sleep duration at follow-up in model A3 ( $B=-0.10, \beta=-0.08, p=0.030)$ but this association was no longer significant when considering

Table 2 Estimates for Cross-Lagged Panel Models for Separate Associations of Local SSS (Model AI), National SSS (Model A2), Income (Model A3) and Education (Model A4) with Sleep Duration: Unstandardized Estimates with 95\% Confidence Intervals in Brackets Followed by Standardized Estimates

\begin{tabular}{|c|c|c|c|}
\hline Model Al & T2 Local SSS & T2 Short Sleep & T2 Long Sleep \\
\hline TI Local SSS & $0.43(0.39 ; 0.47) 0.43^{* * * *}$ & $-0.02^{1}(-.0 .08 ; 0.03)-0.03$ & $-0.03^{1}(-0.09 ; 0.02)-0.05$ \\
\hline TI Short sleep & $-0.21(-0.00 ; 0.44)-0.04^{+}$ & $1.58^{\prime}$ (I.38; I.78) 0.46*** & $-0.80^{1}(-1.19 ;-0.44)-0.24^{* * *}$ \\
\hline TI Long sleep & $0.22(-0.00 ; 0.44) 0.04^{+}$ & $-0.65^{1}(-0.98 ;-0.28) 0.18^{* * *}$ & $1.19^{1}(0.98 ; 1.39) 0.35^{* * *}$ \\
\hline Model A2 & T2 National SSS & T2 Short sleep & T2 Long sleep \\
\hline TI National SSS & $0.4 \mathrm{I}(0.37 ; 0.45) 0.43^{* * *}$ & $-0.07^{1}(-0.12 ;-0.01)-0.09 *$ & $-0.04^{1}(-0.11 ; 0.01)-0.05$ \\
\hline TI Short sleep & $-0.22(-0.45 ;-0.02)-0.05 *$ & I.59' (I.37; I.79) 0.46*** & $-0.69^{1}(-1.03 ;-0.34)-0.21^{* * * *}$ \\
\hline TI Long sleep & $0.04(-0.17 ; 0.26) 0.01$ & $-0.68^{1}(-1.21 ;-0.33)-0.19 * * *$ & $1.16^{1}(0.98 ; 1.36) 0.34 * * *$ \\
\hline Model A3 & T2 Income & T2 Short sleep & T2 Long sleep \\
\hline TI Income & $0.92(0.88 ; 0.95) 0.80 * * *$ & $-0.10^{1}(-0.19 ;-0.01)-0.08^{*}$ & $-0.13^{1}(-0.23 ;-0.00)-0.1 I^{*}$ \\
\hline TI Short sleep & $-0.03(-0.14 ; 0.08)-0.01$ & $1.56^{1}(1.36 ; 1.74) 0.45^{* * * *}$ & $-0.92^{1}(-1.44 ;-0.5 \mathrm{I})-0.27^{* * *}$ \\
\hline TI Long sleep & $0.01(-0.10 ; 0.12) 0.00$ & $-0.77^{1}(-1.14 ;-0.34)-0.21^{* * *}$ & $1.16^{1}(0.95 ; 1.36) 0.33^{* * *}$ \\
\hline Model A4 & T2 Education & T2 Short sleep & T2 Long sleep \\
\hline TI Education & $0.97(0.96 ; 0.99) 0.98^{* * *}$ & $-0.06^{1}(-0.12 ; 0.01)-.07^{+}$ & $-0.03^{1}(-0.09 ; 0.02)-0.04$ \\
\hline TI Short sleep & $-0.04(-0.09 ; 0.02)-0.01$ & $1.56^{\prime}(1.37 ; 1.77) 0.45^{* * * *}$ & $-0.80^{1}(-1.23 ;-0.40)-0.24 * * *$ \\
\hline TI Long sleep & $0.10(0.05 ; 0.15) 0.02 * * *$ & $-0.63^{1}(-1.04 ;-0.27)-0.18^{* * *}$ & $1.17^{1}(0.96 ; 1.37) 0.34 * * *$ \\
\hline
\end{tabular}

Notes: SSS, Subjective Social Status, $\mathrm{TI}=2016, \mathrm{~T} 2=2018$. 'Probit link. ${ }^{*} \mathrm{p}<0.05 ;{ }^{* * *} \mathrm{p}<0.00 \mathrm{I} ;{ }^{+} \mathrm{p}<0.1$. 


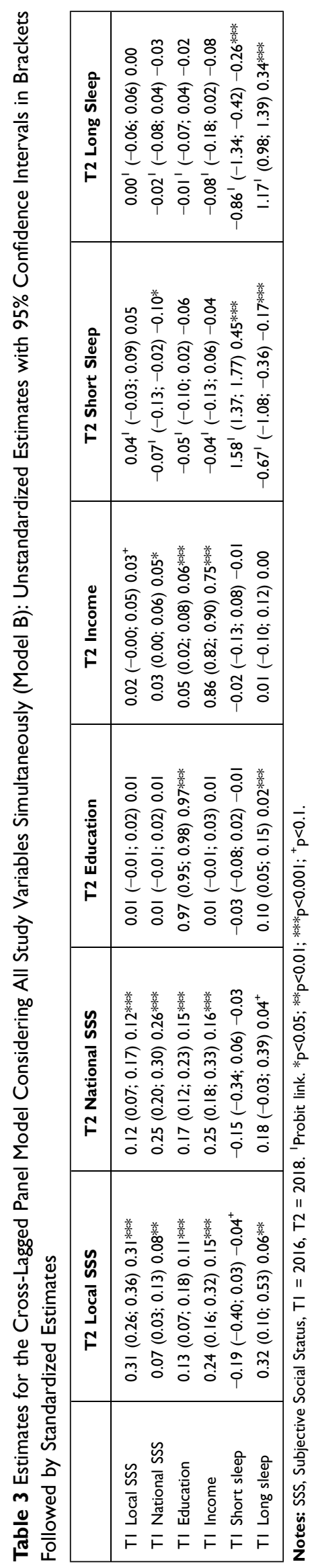

all status indicators simultaneously in model $\mathrm{B}(B=-0.04, \beta$ $=-0.04, p=0.368)$. Lower education at baseline tended to predict short sleep duration at follow-up in model A4 ( $B=$ $-0.07, \beta=-0.06, p=0.098$ ) but this association was also reduced when considering all status indicators simultaneously in model $\mathrm{B}(B=-0.05, \beta=-0.06, p=0.180)$. The loss of significance in associations of income and education with sleep duration could be explained by a mediating role of national SSS. Indeed, half-longitudinal mediation analysis indicated that lower national SSS mediated associations of lower income $(B=-0.017,95 \% C I[-0.033$; $-0.004], p=0.014)$ and lower education $(B=-0.012,95 \%$ $C I[-0.023 ;-0.003], p=0.014)$ with short sleep duration. Turning to a potentially reverse influence, short sleep duration at baseline predicted national SSS at follow-up $(B=$ $-0.22, \beta=-0.05, p=0.028)$ in model A2, but this association was not significant when analyzing all status indicators simultaneously in model B.

\section{Discussion}

This study examined the reciprocal longitudinal associations of both national SSS and local SSS with short sleep duration. To study mutual relations, we applied a crosslagged panel design using data representative for the German population. We found that lower national but not lower local SSS predicted short sleep duration across a time lag of two years beyond the effect of objective social status indicated by income and education. This finding strengthens results from previous cross-sectional research which reported associations between SSS and several indicators of poor sleep. ${ }^{8,21,37-39}$ The present study further extends previous work in this area by showing that national SSS partially mediates associations of both income and education with short sleep duration.

Although a previous meta-analysis ${ }^{22}$ and a former crosslagged panel analysis focusing on SSS and health-related quality of life $\mathrm{e}^{25}$ suggest that both local and national SSS are associated with health, health behavior, and health-related quality of life, respectively, the present analysis suggests that for short sleep duration, only national (but not local) SSS is of predictive relevance. While local SSS captures one's social standing in the local community without explicitly referring to socioeconomic factors, the measurement of national SSS explicitly refers to traditional socioeconomic variables such as income, job position, and education. ${ }^{15,22}$ The present results imply that short sleep duration is not necessarily related to people's perceived social standing across all areas of life. Rather, short sleep duration seems 
to be specifically tied to unfavorable perceptions of one's social position regarding traditional socioeconomic factors (as indexed by national SSS). This assumption is also in line with our finding that low income predicts short sleep duration and that this effect is mediated by national SSS. Possible explanations for this link might be that lower socioeconomic resources result in worse environmental conditions (eg, regarding housing, regarding noise), less favorable working circumstances (eg, need to maximize available time for work), but also in the experience of financial stress which may interfere with adequate sleep. ${ }^{11,12,21,40}$ Importantly, the observed lack of an association between local SSS and short sleep duration does not necessarily imply that one's perceived social position in the closer social environment is irrelevant for sleep duration. As described above, the assessment of local SSS in this and previous research did not explicitly refer to traditional indicators of socioeconomic status and thus attempted to capture a broader range of status-related aspects beyond socioeconomic status (eg, perceived respect and social rewards from others, social standing within meaningful social groups). ${ }^{15,22}$ Possibly local SSS relates to short sleep when it is focused on a comparison regarding traditional indicators of socioeconomic status within one's community. Future research in this direction would thus be of interest.

Based on previous meta-analyses, ${ }^{1,33}$ the present study defined a sleep duration of 6 to 8 hours as the reference category for normal sleep. Former recommendations for normal sleep suggested a sleep duration of 7 to 9 hours as reference category. ${ }^{41}$ Although recent meta-analytic evidence indicates that short sleep defined by a sleep duration of less than 7 hours is not associated with mortality and cardiovascular disease, ${ }^{1}$ several studies have used this categorization in the past. We supplementarily analyzed our data using 7 to 9 hours as reference category and did not observe a social gradient in sleep duration (all $p \mathrm{~s} \geq .1$, data not shown). There was only a trend of national SSS at baseline to predict short sleep duration at follow-up $(B=$ $-0.04, \beta=-0.05, p=0.090$ ) in model A2 (ie, separate analysis of national SSS and sleep duration). In fact, a large proportion of individuals in this study reported to sleep between 6 and $<7$ hours $(n=523 ; 24 \%$ ) which substantially increased the proportion of short sleepers when using $<7$ hours and weakened associations with one's social position.

Although this study focused on short sleep duration, some results for long sleep duration should be mentioned.
Unlike a previous cross-sectional study that reported that lower national SSS relates to longer sleep duration, ${ }^{42}$ neither national SSS nor local SSS predicted long sleep duration in this longitudinal study. Lower income at baseline predicted long sleep duration at follow-up in the separate model (ie, model A3), but this association did not remain when considering all variables of subjective and objective social status simultaneously in model B. Conversely, we found that long sleep duration predicted higher education and higher local SSS at follow-up and tended to predict higher national SSS in the full model. These findings are interesting and require further investigation.

Notwithstanding the strengths of the present study such as the cross-lagged panel design, as well as the simultaneous examination of local SSS, national SSS, and objective social status, limitations need to be reflected. First, because we studied a representative sample from the German population, the generalizability to other nations or cultures is an open question. Second, there are no established conventions to interpret effect sizes in CLPMs. These effects are usually substantially smaller than in cross-sectional studies since cross-lagged effects control for stability effects. Although this is a common problem with respect to CLPMs, awareness of this issue is important. ${ }^{43}$ Third, half-longitudinal mediation $^{34}$ is the only method for two-wave studies to test for mediation. This method, however, is restricted as it can only test for partial mediation. Future studies with at least 3 waves are necessary and it may also be promising to include further potential mediators such as perceived financial stress, health behavior, or environmental factors. ${ }^{14,15,44}$ Fourth, we only assessed individuals' self-rated sleep duration which might deviate from objective measures. ${ }^{45}$ Finally, this study did not include sleep quality which is another important factor of sleep health ${ }^{46}$ and thus the present study does not speak to the longitudinal associations of SSS with all potentially relevant sleep dimensions.

To conclude, this study provides the first evidence for a prospective association between low national SSS and short sleep duration. Future studies on socioeconomic status and sleep should take subjective measures of social status into account to gain a clearer picture of the social determinants of sleep.

\section{Disclosure}

The authors report no conflicts of interest in this work. 


\section{References}

1. Itani O, Jike M, Watanabe N, Kaneita Y. Short sleep duration and health outcomes: a systematic review, meta-analysis, and meta-regression. Sleep Med. 2017;32:246-256. doi:10.1016/j. sleep.2016.08.006

2. Krueger PM, Friedman EM. Sleep duration in the United States: a cross-sectional population-based study. Am J Epidemiol. 2009;169 (9):1052-1063. doi:10.1093/aje/kwp023

3. Jarrin DC, McGrath JJ, Quon EC. Objective and subjective socioeconomic gradients exist for sleep in children and adolescents. Heal Psychol. 2014;33(3):301-305. doi:10.1037/a0032924

4. Whinnery J, Jackson N, Rattanaumpawan P, Grandner MA. Short and Long Sleep Duration Associated with Race/ Ethnicity, Sociodemographics, and Socioeconomic Position. Sleep. 2014;37 (3):601-611. doi:10.5665/sleep.3508

5. Jehan S, Myers AK, Zizi F, et al. Sleep health disparity: the putative role of race, ethnicity and socioeconomic status. Sleep Med Disord Int J. 2018;2(5):127-133.

6. Metse AP, Bowman JA. Prevalence of self-reported suboptimal sleep in Australia and receipt of sleep care: results from the 2017 National Social Survey. Sleep Heal. 2020;6(1):100-109. doi:10.1016/j. sleh.2019.08.010

7. Saini EK, Keiley MK, Fuller-Rowell TE, Duke AM, El-Sheikh M. Socioeconomic Status and Sleep among Couples. Behav Sleep Med. 2020;1-19. doi:10.1080/15402002.2020.1721501

8. Widome R, Jensen A, Fu SS. Socioeconomic Disparities in Sleep Duration Among Veterans of the US Wars in Iraq and Afghanistan Am J Public Health. 2015;105(2):e70-e74. doi:10.2105/ AJPH.2014.302375

9. Zhu G, Catt M, Cassidy S, et al. Objective sleep assessment in $>80,000$ UK mid-life adults: associations with sociodemographic characteristics, physical activity and caffeine. PLoS One. 2019;14 (12):e0226220. doi:10.1371/journal.pone.0226220

10. Adler NE, Ostrove JM. Socioeconomic Status and Health: what We Know and What We Don't. Ann N Y Acad Sci. 1999;896(1):3-15. doi:10.1111/j.1749-6632.1999.tb08101.x

11. Van Cauter E, Spiegel K. Sleep as a Mediator of the Relationship between Socioeconomic Status and Health: a Hypothesis. Ann N Y Acad Sci. 1999;896(1):254-261. doi:10.1111/j.1749-6632.1999. tb08120.x

12. Matthews KA, Gallo LC. Psychological perspectives on pathways linking socioeconomic status and physical health. Annu Rev Psychol. 2011;62:501-530. doi:10.1146/annurev.psych.031809.130711

13. Cohen S, Alper CM, Doyle WJ, Adler N, Treanor JJ, Turner RB. Objective and subjective socioeconomic status and susceptibility to the common cold. Health Psychol. 2008;27(2):268-274. doi:10.1037/ 0278-6133.27.2.268

14. Hoebel J, Lampert T. Subjective social status and health: multidisciplinary explanations and methodological challenges. $J$ Health Psychol. 2018;25(2):135910531880080. doi:10.1177/13591053188 00804

15. Euteneuer F. Subjective social status and health. Curr Opin Psychiatry. 2014;27(5):337-343. doi:10.1097/YCO.00000000 00000083

16. Demakakos P, Nazroo J, Breeze E, Marmot M. Socioeconomic status and health: the role of subjective social status. Soc Sci Med. 2008;67 (2):330-340. doi:10.1016/j.socscimed.2008.03.038

17. Fournier MA. Dimensions of human hierarchy as determinants of health and happiness. Curr Opin Psychol. 2020;33:110-114. doi:10.1016/j.copsyc.2019.07.014

18. Singh-Manoux A, Marmot MG, Adler NE. Does Subjective Social Status Predict Health and Change in Health Status Better Than Objective Status? Psychosom Med. 2005;67(6):855-861. doi:10.1097/01.psy.0000188434.52941.a0
19. Schneider SM. Why Income Inequality Is Dissatisfying - Perceptions of Social Status and the Inequality-Satisfaction Link in Europe. Eur Sociol Rev. 2019;35(3):409-430. doi:10.1093/esr/jcz003

20. Pickett KE, Wilkinson RG. Income inequality and health: a causal review. Soc Sci Med. 2015;128:316-326. doi:10.1016/j. socscimed.2014.12.031

21. Jarrin DC, McGrath JJ, Silverstein JE, Drake C. Objective and Subjective Socioeconomic Gradients Exist for Sleep Quality, Sleep Latency, Sleep Duration, Weekend Oversleep, and Daytime Sleepiness in Adults. Behav Sleep Med. 2013;11(2):144-158. doi:10.1080/15402002.2011.636112

22. Zell E, Strickhouser JE, Krizan Z. Subjective social status and health: a meta-analysis of community and society ladders. Heal Psychol. 2018;37(10):979-987. doi:10.1037/hea0000667

23. Richter D, Schupp J, Innovation Sample SOEP. (SOEP-IS) description, Structure and Documentation. SSRN Electron J. 2012. doi: $10.2139 /$ ssrn.2131214

24. Britzke J, Schupp J SOEP Wave Report 2016. Berlin; 2017. https:// www.diw.de/documents/publikationen/73/diw_01.c.560446.de/wave report_2016.pdf. Accessed June 2, 2021.

25. Euteneuer F, Schäfer SJ, Neubert M, Rief W, Süssenbach P. Subjective social status and health-related quality of life-A cross-lagged panel analysis. Heal Psychol. 2021;40(1):71-76. doi:10.1037/HEA0001051

26. Euteneuer F, Süssenbach P, Schäfer S, Rief W. MacArthur Scales for Subjective Social Status in the Social Environment (SSS-U) and in Germany (SSS-D) [Subjektiver sozialer Status. MacArthur-Skalen zur Erfassung des wahrgenommenen sozialen Status im sozialen Umfeld (SSS-U) und in Deutschland (SSS-D)]. Verhaltenstherapie. 2014;25:229-232. doi:10.1159/000371558

27. Goodman E, Adler NE, Kawachi I, Frazier AL, Huang B, Colditz GA. Adolescents' Perceptions of Social Status: development and Evaluation of a New Indicator. Pediatrics. 2001;108(2):e31. doi:10.1542/peds.108.2.e31

28. Adler NE, Epel ES, Castellazzo G, Ickovics JR. Relationship of Subjective and Objective Social Status With Psychological and Physiological Functioning: preliminary Data in Healthy White Women. Heal Psychol. 2000;19(6):586-592. doi:10.1037//02786133.19.6.586

29. Cohen S. Social status and susceptibility to respiratory infections. Ann N Y Acad Sci. 1999;896(1):246-253. doi:10.1111/j.17496632.1999.tb08119.x

30. Cundiff JM, Smith TW, Uchino BN. Subjective Social Status: construct Validity and Associations with Psychosocial Vulnerability and Self-Rated Health. Int J Behav Med. 2011. doi:10.1007/s12529-0119206-1

31. Dudel C, Garbuszus JM, Schmied J. Assessing differences in household needs: a comparison of approaches for the estimation of equivalence scales using German expenditure data. Empir Econ. 2020;1-31. doi:10.1007/s00181-020-01822-6

32. SOEP-IS Group. PGEN: Person-Related Status and Generated Variables. SOEP Sur-Vey Papers 511: Series D - Variable Descriptions and Coding. Berlin: DIW Berlin/SOEP; 2018.

33. Jike M, Itani O, Watanabe N, Buysse DJ, Kaneita Y. Long sleep duration and health outcomes: a systematic review, meta-analysis and meta-regression. Sleep Med Rev. 2018;39:25-36. doi:10.1016/J. SMRV.2017.06.011

34. Cole DA, Maxwell SE. Testing Mediational Models With Longitudinal Data: questions and Tips in the Use of Structural Equation Modeling. J Abnorm Psychol. 2003;112(4):558-577. doi:10.1037/0021-843X.112.4.558

35. Allison PD. Estimation of Linear Models with Incomplete Data. Sociol Methodol. 1987;17(November):71-103. doi:10.2307/271029

36. Young R, Johnson DR. Methods for Handling Missing Secondary Respondent Data. J Marriage Fam. 2013;75(1):221-234. doi:10.1111/j.1741-3737.2012.01021.x 
37. Miyakawa M, Magnusson Hanson LL, Theorell T, Westerlund H. Subjective social status: its determinants and association with health in the Swedish working population (the SLOSH study). Eur J Public Health. 2012;22(4):593-597. doi:10.1093/eurpub/ckr064

38. Huynh VW, Chiang JJ. Subjective Social Status and Adolescent Health: the Role of Stress and Sleep. Youth Soc. 2018;50 (7):926-946. doi:10.1177/0044118X16646028

39. Sweenie R, Basch M, Ding K, et al. Subjective social status in adolescents with asthma: psychosocial and physical health outcomes. Heal Psychol. 2020;39(3):172-178. doi:10.1037/ hea0000822

40. Etindele Sosso F, Papadopoulos D, Surani S, Curcio G. Sleep Disturbances are Consequences or Mediators between Socioeconomic Status and Health: a Scoping Review. May. 2019. doi:10.20944/PREPRINTS201905.0353.V1

41. Watson NF, Badr MS, Belenky G, et al. Recommended Amount of Sleep for a Healthy Adult: a Joint Consensus Statement of the American Academy of Sleep Medicine and Sleep Research Society. Sleep. 2015;38(6):843-844. doi:10.5665/sleep.4716
42. Patel SR, Malhotra A, Gottlieb DJ, White DP, Hu FB. Correlates of Long Sleep Duration. Sleep. 2006;29(7):881-889. doi:10.1093/sleep/ 29.7.881

43. Adachi P, Willoughby T. Interpreting effect sizes when controlling for stability effects in longitudinal autoregressive models: implications for psychological science. Eur J Dev Psychol. 2015;12 (1):116-128. doi:10.1080/17405629.2014.963549

44. Cundiff JM, Boylan JM, Muscatell KA. The Pathway From Social Status to Physical Health: taking a Closer Look at Stress as a Mediator. Curr Dir Psychol Sci. 2020;096372142090159. doi:10.1177/0963721420901596

45. Lauderdale DS, Knutson KL, Yan LL, Liu K, Rathouz PJ. Sleep duration: how well do self-reports reflect objective measures? The CARDIA Sleep Study. Epidemiology. 2008;19(6):838. doi:10.1097/ EDE.0B013E318187A7B0

46. Bin YS. Is Sleep Quality More Important Than Sleep Duration for Public Health? Sleep. 2016;39(9):1629-1630. doi:10.5665/sleep.6078

\section{Publish your work in this journal}

Nature and Science of Sleep is an international, peer-reviewed, open access journal covering all aspects of sleep science and sleep medicine, including the neurophysiology and functions of sleep, the genetics of sleep, sleep and society, biological rhythms, dreaming, sleep disorders and therapy, and strategies to optimize healthy sleep.
The manuscript management system is completely online and includes a very quick and fair peer-review system, which is all easy to use. Visit http://www.dovepress.com/testimonials.php to read real quotes from published authors. 